\title{
Remedial Use of Withanolides from Withania Coagolans (Stocks) Dunal
}

\author{
Maryam Khodaei $^{1}$, Mehrana Jafari ${ }^{2, *}$, Mitra Noori ${ }^{2}$ \\ ${ }^{1}$ Dept of Chemistry, University Of Sistan \& Baluchestan, Zahedan Post Code: 98135-674 Islamic republic of Iran \\ ${ }^{2}$ Dept. of Biology, University of Arak, Arak, Post Code: 38156-8-8349, Islamic republic of Iran
}

\begin{abstract}
Withanolides are a branch of alkaloids, which reported many remedial uses. Withanolides mainly exist in 58 species of solanaceous plants which belong to 22 generous. In this review, the phyochemistry, structure and synthesis of withanolieds are described. Withania coagulans Dunal belonging to the family Solanaceae is a small bush which is widely spread in south Asia. In this paper the biological activities of withanolieds from Withania coagulans described. Anti-inflammatory effect, anti cancer and alzheimer's disease and their mechanisms, antihyperglycaemic, hypercholesterolemic, antifungal, antibacterial, cardiovascular effects and another activity are defined. This review described 76 compounds and structures of Withania coagulans.
\end{abstract}

Keywords Withanolides, Withania Coagulans, Solanaceae, Biological Activity

\section{Introduction}

Withania coagulans Dunal is very well known for its ethnopharmacological activities (Kirthikar and Basu 1933). The W. coagulans, is common in Iran, Pakistan, Afghanistan and East India, also used in folk medicine. Fruits of the plant have a milk-coagulating characteristic (Atal and Sethi 1963). The fruits have been used for milk coagulation which is attributed to the enzymatic charisma of the plant (Naz et al 2009). The fruits are sweet and are reported to be sedative, emetic, alterative and diuretic. They are useful in chronic disorders of liver. The fruits are also used in dyspepsia, flatulent coli and other intestinal infections. They are employed for treatment of asthma, biliousness and strangury. In some parts of the Indian sub-continent, the berries are used as a blood purifier. The twigs are chewed for cleaning teeth and the smoke of the plant is inhaled for relief of toothache (Kirthikar and Basu 1933). Chadha (1976) said Withania coagulans is also known as a treatment of ulcers, rheumatism, bronchitis, and degenerative diseases. (Refer to Atta-urRahman 1998 -e)

\subsection{Taxonomical Classification}

Genus: Withania,

Family: Solonaceae,

Subfamily: Solanoideae,

Tribe: Physaleae,

* Corresponding author:

jafari.mehrana@yahoo.com (Mehrana Jafari)

Published online at http://journal.sapub.org/als

Copyright (C) 2012 Scientific \& Academic Publishing. All Rights Reserved
Subtribe: Withaninae,

Species: Withania coagulans (Stocks) Dunal. (Hemalatha et al. 2008)

\subsection{Distribution}

Drier parts of Punjab, Gujarat, Simla and Kumaon in India, Baluchestan in Iran, Pakistan and Afghanistan.

\subsection{Synonyms}

English: Vegetable Rennet, Indian-Cheese-maker, UnaniDesi Asgandh, Kaaknaj-e-Hindi, Paneer, Paneer-band, Akri (fruit), Siddha/Tamil-Ammukkura.

Local names: This plant is known by different names, in different local languages, such as 'Akri' or 'Puni-ke-bij' in Hindi, 'Tukhme-kaknaje-hidi' in Persian. 'Spiubajja' in Afghan, 'Khamjira' in Punjabi and 'Punirband' or 'Punir- ja -fota' in Sindhi (Naz 2002).

\subsection{Botanical Description}

$W$. coagulans is a rigid gray-whitish small shrub, 30-90 $\mathrm{cm}$ tall, leaves $2.5-7.5 \mathrm{~cm}$ by $1.5 \mathrm{~cm}$, usually lanceolate oblong, sometimes ovate, obtuse, entire, and narrowed at the base and very short stalked. They are densely covered with minute, gray, stellated tomentum. Flowers are 7-12 mm across, yellow dioeciously and polygamous. They are in axillary cymose clusters, leathery calyx; seeds are dark brown, ear shaped, glabrous, pulp brown, having sharp fruity smell (Dymock et al 1893).

\subsection{Useable Part}

Whole plant, roots, leaves, stem, green berries, fruits, seeds and bark are used. 
Fruits: Carminative, depurative, used for dyspepsia, flatulence and strange. The properties are attributed to the pulp and husk of the berry. The berries contain a milk- coagulating enzyme, esterase, free amino acids, fatty oil, an essential oil and alkaloids (Khare 2007). The milk- coagulating activity is due to the presence of an enzyme, under optimum conditions (Atal and Sethi 1963). Ashwagandha (Bengali) and Ashwagandhi (Kannada) are confusing synonyms of $W$. coagulans (Khare 2007).

Seeds: anti-inflammatory, emetic, diuretic, emmenagogue.

Leaf: alterative, febrifuge.

\section{Withanolides}

The term "withanolide" is a structural term that has been used for "withan" from the genus Withania, and "olide" is chemical term for a lactone. To this date, about 400 withanolides or closely related congeners have been discovered in altogether 58 solanaceous species belonging to 22 genera (Eich 2008). Withanolides have been discovered also in certain Tacca spp. of the Taccaceae (taccalonolides) (Huang et al 2002) and Ajuga spp., e.g., A. parviflora Benth. Lamiaceae (ajugins) (Khan et al 1999), as well as in some marine organisms. Nevertheless, their occurrence in the Solanaceae is predominating by far (Eich 2008). Different withanolides, withacoagin and coagulan reported from $W$. coagulans. Withaferin A (Steroidal lactones of withanolide series) had been isolated from fruits of $W$. coagulans (Khare 2007).

\subsection{Structures}

Withanolides of ergostan steroids are four-ring triterpenes. The plant steroids are derived from sterols and comprise steroid saponins, steroid alkaloids, pregnanes, androstanes, estranes, ecdysteroids, withanolides and cardiac glycosides (Kreis and Muller-Uri 2010). "Withanolide" represents the term for the C28-skeleton 22-hydroxyergostan-26-oic acid -22, 26-olide; this $\gamma$-lactones residue containing the structure is a theoretical (Lavie et al $1965 \mathrm{a}, \mathrm{b}$ ). The basic skeleton of withanolides is shown in Figure 1.

Basically there are two major groups of withanolides as follows:

A- Withanolides with an unmodified skeleton

a) With a regular $\beta$-oriented side chain

b) With an unusual $\alpha$-oriented side chain.

B- Withanolides with modified carbocyclic skeletons or side chains. These withanolides are initially classified on the basis of the chemotypes of the Withania species depending on the region of the collected plant. Chemically, these compounds may be classified as ergostane derivatives from their structural pattern; these can be broadly divided into seven groups.

1. $5 \beta, 6 \beta$-epoxides

2. $6 \alpha, 7 \alpha$-epoxides
3. 5-enes

4. Intermediate compounds

$5.5 \alpha, 6 \alpha$-epoxides

6. $6 \beta, 7 \beta$-epoxides

7. Phenolic withanolides (Glotter 1991).

Among these, the $5 \beta, 6 \beta$-epoxides are most common. Most of the compounds possess a $4 \beta$-hydroxyl group. Purushothaman and Vasanth (1989) extracted four-ring compound which possess $\alpha, \beta$-unsaturated- $\gamma$-lactone system, in e.g. ixocarpa- lactone A. (Refer into Atta-ur-Rahman 1998e). Ray (1989) showed that the withanolides which possess $6 \alpha$ and $7 \alpha$-epoxides generally contain $5 \alpha$-hydroxyl and are believed to originate from $5 \beta, 6 \beta$-epoxides (Refer to Atta-urRahman 1998e).

\subsection{Synthesis}

Withanolides generally contain a polyoxygenated ergostan skeleton. One of the characteristics is the ability to introduce oxygen functions in almost every position of the carrbocyclic skeleton and side chain of compounds of this type (Naz 2002). Withanoloieds are synthesized via the mevalonate pathway of terpenoids formation and arise from the initial cyclization of 3S-squalene-2, 3-epoxide (Kreis and Muller-Uri 2010).

\subsection{Phytochemistry}

Different phytochemistry studies have been done on $W$. coagulans and various compounds have been isolated from the plant. The phytochemical investigations on $W$. coagulans up to 2011 reported a number of phytoconstituents. The most important constitutions of $W$. coagulans are shown in Table 1 and their structures are shown in Figure 2.

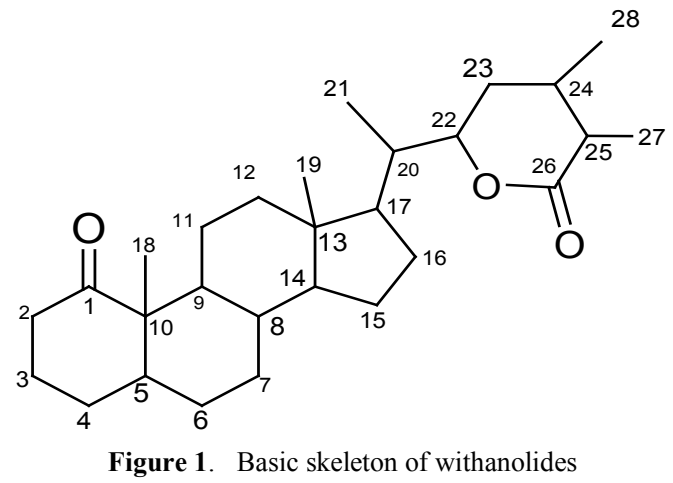

\section{Remedial Uses}

\subsection{Anti-Inflammatory Effect}

The alcoholic extract of $W$. coagulans showed significant anti-inflammatory effects in acute inflammation induced with egg albumin. Sub-acute inflammation induced with formalin and granulation tissues were formed by cotton pellet method (Budhiraja et al 1977). Budhiraja et al (1986) reported Anti-inflammatory activity of a withanolide from W. coagulans. 
Name/Constituents

(20R, 22R) $6 \alpha, 7 \alpha$ - epoxy- 5 $\alpha, 20$-dihydroxy- 1- oxo- with a-2 ,24- dienolide

(20S, 22R) $6 \alpha, 7 \alpha$ - epoxy- 5 -hydroxy- 1 - oxo- witha- 2,24 - dienolide

(22R), 20ß-hydroxy- 1-oxowitha- 2,5,24- trienolide

(22R)-14,20-epoxy-17ß-hydroxy-1-oxowitha-3,5,25-trienolide

[14 $\alpha, 20 \beta, 27$ - trihydroxy- 1-oxo-(22R)- with a-3,5,24-trienolide]

$14,15 \beta$ - epoxywithanolide I: [(20S, 22R) 17 $\beta, 20 \beta$-dihyroxy $-14 \beta, 15 \beta$ - epoxy- 1 -

oxo- witha-3,5,24- trienolide]

$17 \beta$ - hydroxywithanolide $\mathrm{K}$ :

[(20S, 22R) $14 \alpha, 17 \beta, 20 \beta$-trihydroxy 1- oxo- with a-2, 5, 24- trienolide]

$17 \beta, 27$ dihydroxy-14, 20- epoxy -1- oxo- 22R- witha-3, 5, 24- trienolide

$17 \beta, 20 \beta$ - dihydroxy- 1- oxo- witha- 2,5,24- trienolide

17 $\beta$-hydroxy-14 $\alpha, 20 \alpha$-epoxy-1-oxo-(22R)-witha-3,5,24-trienolide

$20 \beta$, hydroxy -1- oxo- (22R) - witha - 2, 5. 24- trienolide

$3 \beta, 14 \alpha, 20 \alpha_{\mathrm{F}}, 27-$ tetrahydroxy-1-oxo-20R,22R-witha-5,24-dienolide

3ß-hydroxy- 2,3-dihydrowithanolide $\mathrm{F}$

5,20 $\alpha$ (R)-dihydroxy- $6 \alpha, 7 \alpha$-epoxy-1-oxo- $(5 \alpha)$ witha-2,24-dienolide

$5 \alpha, 17 \alpha$ - dihydroxy- 1 - oxo- $6 \alpha, 7 \alpha$ - epoxy- 22 R- with a- 2,24 - dienolide

$5 \alpha, 20 \alpha(\mathrm{R})$ dihydroxy- $6 \alpha, 7 \alpha$ - epoxy-1- oxowitha- 2,24 - dienolide

$5 \alpha, 27$ - dihydroxy- $6 \alpha, 7 \alpha$ - epoxy-1-oxowitha- 2,24 - dienolide

(20R,22R)-14,20a,27-trihydroxy-1-oxowitha-3,5,24-trienolide

Ajugin A

Ajugin E

Amyrin

Chlorogenic acid

Coagulanolide:

(17S,20S,22R)-14 $\alpha, 15 \alpha, 17 \beta, 20 \beta$-tetrahydroxy-1-oxowitha-2,5,24-trienolide

Coagulansins A

Coagulansins B

Coagulin

Coagulin A

Coagulin B

Coagulin C

Coagulin D

Coagulin E

Coagulin F:

[27-hydroxy-14,20-epoxy-1-oxo- (22R)-witha-3,5,24-trienolide]

Coagulin G:

[17â,27-dihydroxy-14,20-epoxy-1-oxo-(22R)- witha-2,5,24-trienolide]

Coagulin $\mathrm{H}$ :

$5 \alpha, 6 \beta, 14 \alpha, 15 \alpha, 17,20$ - hexahydroxy- 1- oxo- witha - 2,24 - dienolide

Coagulin I:

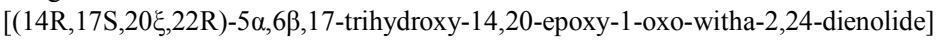

Coagulin $\mathrm{J}$ :

$3 \beta, 27$ dihydroxy- 14, 20 epoxy-1-oxowithania-5, 24-dienolide

Coagulin K:

14,20- Epoxy- 3ß-(O- $ß-\mathrm{D}$-glucopyranosyl) -1- oxowitha- 5,24-dienolide

Coagulin L:

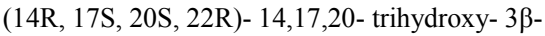

(O- $\beta$-D-glucopyranosyl)-1-oxowitha-5, 24- dienolide

Coagulin $\mathrm{M}$ :

$5 \alpha, 6 \beta, 27$ - trihydroxy- 14, 20- epoxy- 1- oxo- witha- 24 enolide

Coagulin $\mathrm{N}$ :

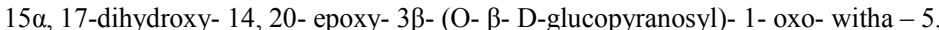
24- dienolide

structure

2

3

4

5

6

7

8

9

10

11

12

13

14

15

16

17

18

19

20

21

22

22

23

24

25

26

27

28

29

30

30

31 part of plant

Root

Root

Whole plant

Whole plant

Whole plant

Whole plant

Whole plant

Whole plant

Whole plant

Whole plant

Fruit

Fruit

Fruit

leave

Fruit

Fruit

Fruit

Aerial parts

Whole plant

Aerial part

Whole plant

Leave

Fruit

Whole plant

Whole plant

Whole plant

Whole plant

Aerial part

Aerial part

Aerial part

Aerial part

Whole plant

Whole plant

Whole plant

Whole plant

Whole plant

Whole plant

Whole plant

Whole plant

Whole plant
References

Neogi et al 1988

Neogi et al 1988

Naz 2002

$\mathrm{Naz} 2002$

Dur- E- Shahwar. 1999

Choudhary et al 1995

Choudhary et al 1995

Atta-ur- Rahman et al 1993

Choudhary et al 1995

Atta-ur-Rahman et al 2003

Atta-ur-Rahman et al 2003

Ramaiah et al 1984

Budhiraja et al 1983

Subramanian et al 1971

Anonymous 1966

Anonymous 1966

Anonymous 1966

Huang et al 2009

$\mathrm{Naz} 2002$

Nawaz et al 1999

$\mathrm{Naz} 2002$

Anonymous 1966

Maurya et al 2008

Jahan et al 2010

Jahan et al 2010

Dur- E- Shahwar 1999

Dur- E- Shahwar 1999

Atta-ur- Rahman et al 1998

(a)

Atta-ur- Rahman et al 1998

Atta-ur- Rahman et al 1998(c)

Atta-ur- Rahman et al 1998(c)

Atta-ur- Rahman et al 1998

(a)

Atta-ur- Rahman and Choudhary et al 1998 (a)

Atta-ur- Rahman et al 1998(d)

Atta-ur-Rahman et al 1998 (d)

Atta-ur- Rahman et al 1998(d)

Atta-ur- Rahman et al 1998(d)

Atta-ur- Rahman et al 1998(d)

Atta-ur- Rahmant et al 1998

(b)

Atta-ur- Rahman et al 1998(b) 
Coagulin O:

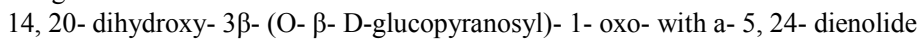
Coagulin P:

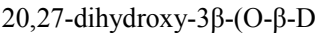

-glucopyranosyl)-1-oxo-(20S,22R)-witha-5,14,24-trienolide,

Coagulin Q:

( 20S,22R)-1 $\alpha, 3 \beta, 20$-Trihydroxy-witha-5,24-dienolide 3-O- $\beta$-D-glucopyranoside

Coagulin R:

3ß,17ß-dihydroxy-14,20-epoxy-1-oxo-(22R)-witha-5,24-dienolide

Coagulin $\mathrm{S}$ :

$(20 \mathrm{~S}, 22 \mathrm{R})$ - $5 \alpha, 6 \beta, 14 \alpha, 15 \alpha, 17 \beta, 20,27$ - heptahydroxy- 1- oxo- witha -24- enolide

Coagulin U

D- Arabinose

D- Galactose

Ergosta-5,25-diene-3ß,24 $\varepsilon$-diol

Linoleic acid

Methyl-4 - benzoate

ß-sitosterol

ß-sitosterol glycoside

Withacoagin

Withacoagulin:

20ß,27-Dihydroxy-1-oxo-(22R)-witha-2,5,24-tetraenolide

Withacoagulin A:

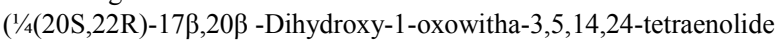

Withacoagulin B:

(1/4(20R,22R)-20ß,27-Dihydroxy-1-oxowitha-3,5,14,24-tetraenolide

Withacoagulin C:

(1/4(20S,22R)-14a,15a,17ß,20ß -Tetrahydroxy-1-oxowitha-3,5,24-trienolide

Withacoagulin D:

(1/4(20S,22R)-14a,17ß,20ß,27-Tetrahydroxy-1-oxowitha-3,5,24-trienolide

Withacoagulin E:

(1/4(20R,22R)-14 $\beta, 20 \beta$-Dihydroxy-1-oxowitha-2,5,24-trienolide

Withacoagulin F:

(1/4(20R,22R)-14 $3,20 \beta$-Dihydroxy-1-oxowitha-3,5,24-trienolide

Withaferin

Withaferin A

Withahejarin:

[ $20 \beta$-hydroxy-1-oxo-(22R) - witha- 2,5,24 trienolide

Withanolide D

$\Delta^{3}$ isowithanolide $\mathrm{F}$

Withanolide $\mathrm{F}$

Withanolide G

Withanolide $\mathrm{H}$ :

$14 \alpha, 20 \alpha_{\mathrm{F}}, 27$-trihydroxy-1-oxo-20R, 22R-with a-2,5,24- trienolide

withanolide I

withanolide J

Withanolide K

Withanolide L

Withapakistanin:

[ $17 \beta, 20 \beta$ - dihydroxy- 14, 15 $\beta$ - epoxy-1-oxo-(22R)- with a-3,5,24 trienolide]

Withasomniferine-A: [ $17 \beta$, hydroxyl- $6 \alpha, 7 \alpha$

-epoxide-1-oxo-(22R)-witha-4,24-dienolide]

(22R)-14a,15a,17b,20b-tetrahydroxy-1-oxowitha-2,5,24-trien-26,22-olide
Atta-ur- Rahman et al 1998

(b)
Whole plant

Whole plant

Whole plant

Whole plant

Whole plant

Seed

Seed

Fruit

Seed

Whole plant

Whole plant

Whole plant

Root

Fruit

Aerial parts

Aerial parts

Aerial parts

Aerial parts

Aerial parts

Aerial parts

Fruit

Roots

Whole plant

Fruit

Whole plant

Aerial parts

Whole plant

Fruit

Whole plant

Whole plant

Whole plant

Aerial parts

Whole plant

Whole plant

Aerial parts
Atta-ur-Rahman et al 1999

Atta-ur-Rahman et al 1999

Atta- ur- Rahman et al 1999

Nur-E-Alam et al 2003

Naz 2002

Anonymous 1966

Anonymous 1966

Velde et al 1983

Anonymous 1966

Naz 2002

$\mathrm{Naz} 2002$

Naz 2002

Neogi et al 1988

Atta-ur-Rahman et al 2003

Huang et al 2009

Huang et al 2009

Huang et al 2009

Huang et al 2009

Huang et al 2009

Huang et al 2009

Neogi et al 1988

Subramanian and Sethi 1969

Dur- E- Shahwar. 1999

Budhiraja et al 1983

Velde et al 1983

Huang et al 2009

Gottlieb et al 1981 (refer to Atta-ur-Rahman 1998-e)

Ramaiah et al 1984

Gottlieb et al 1981 (refer to Atta-ur-Rahman 1998-e)

Gottlieb et al 1981 (refer to Atta-ur-Rahman 1998-e)

Gottlieb et al 1981 (refer to Atta-ur-Rahman 1998-e)

Huang et al 2009

Dur- E- Shahwar. 1999

Dur- E- Shahwar. 1999

Huang et al 2009 


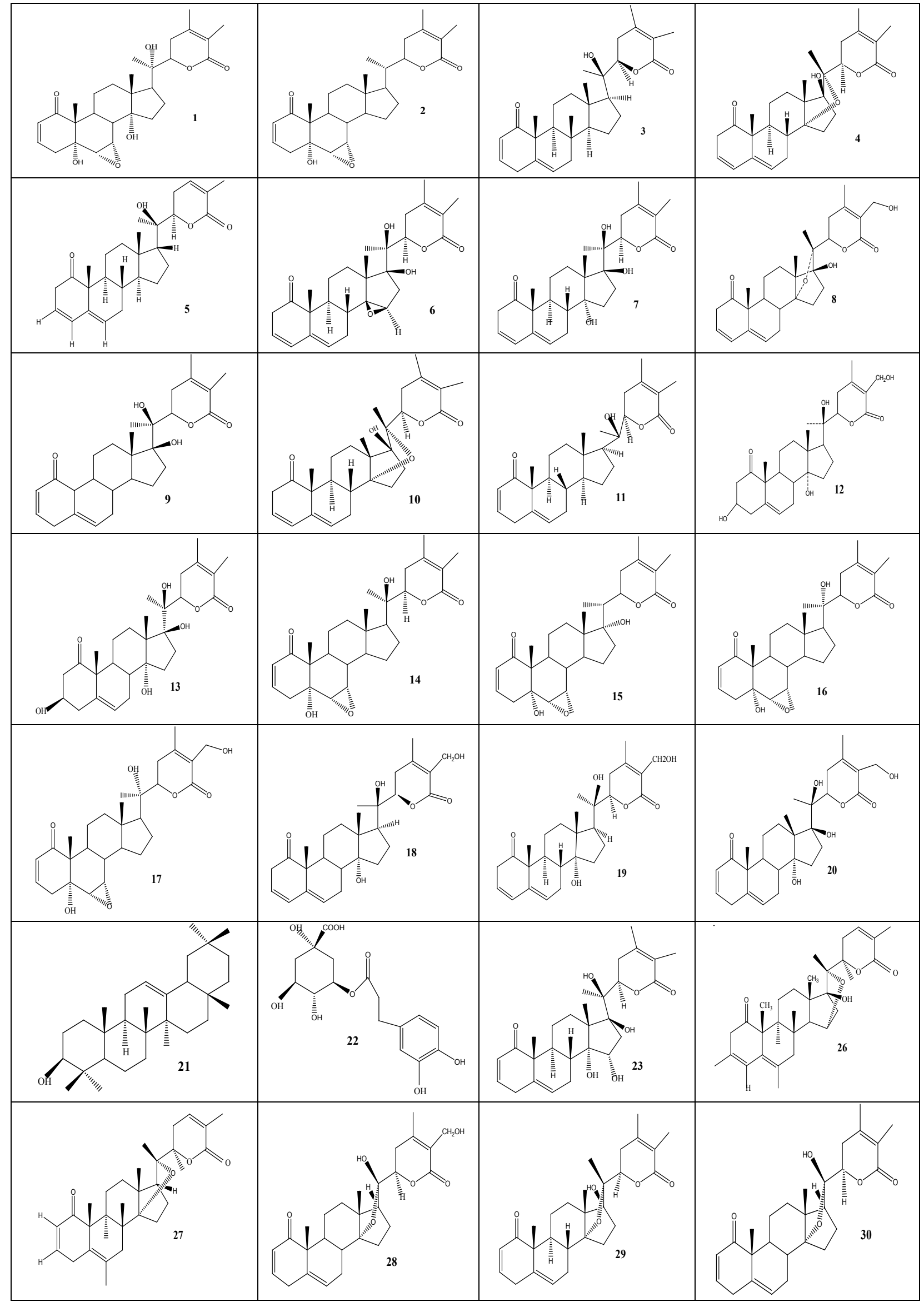




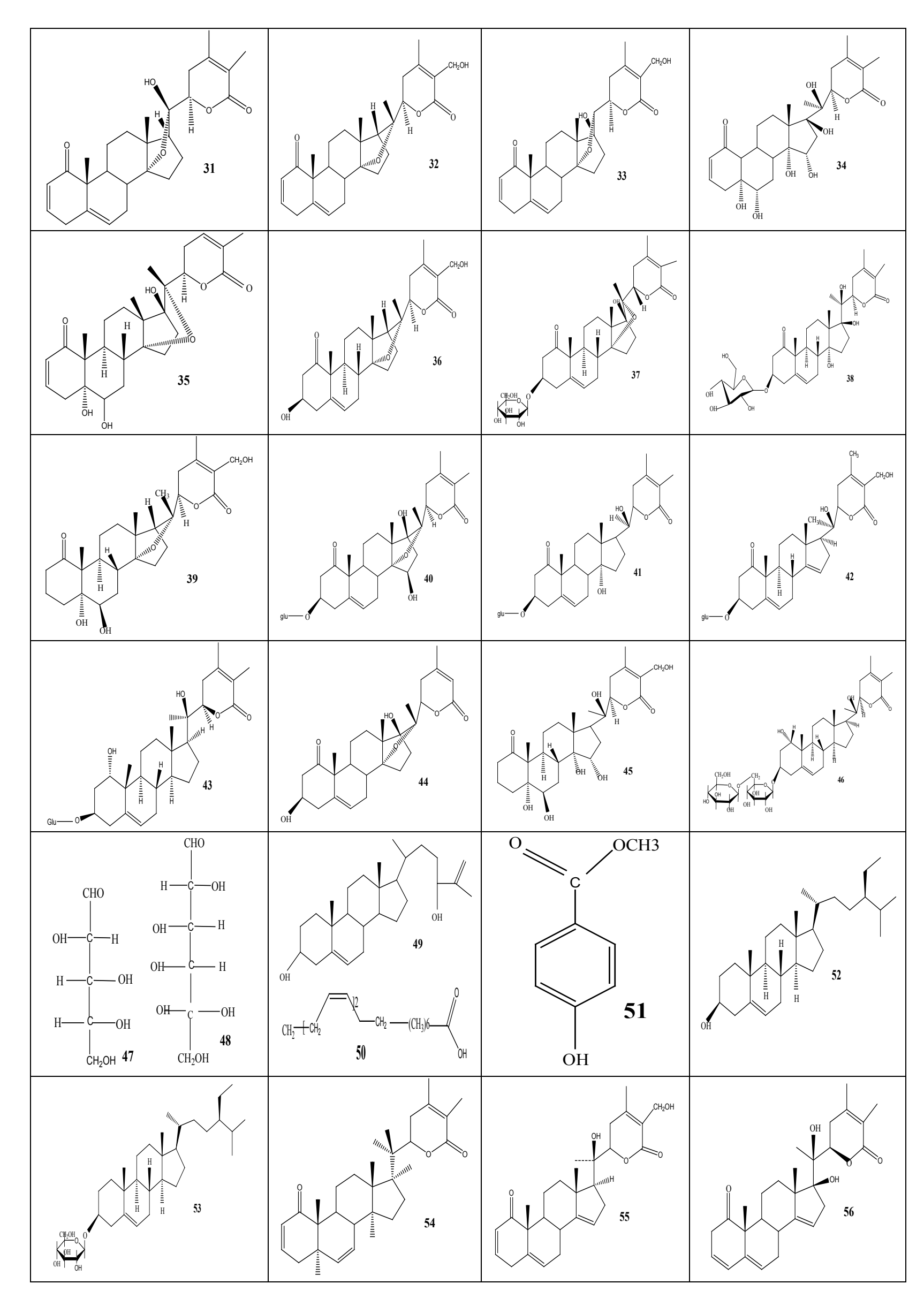




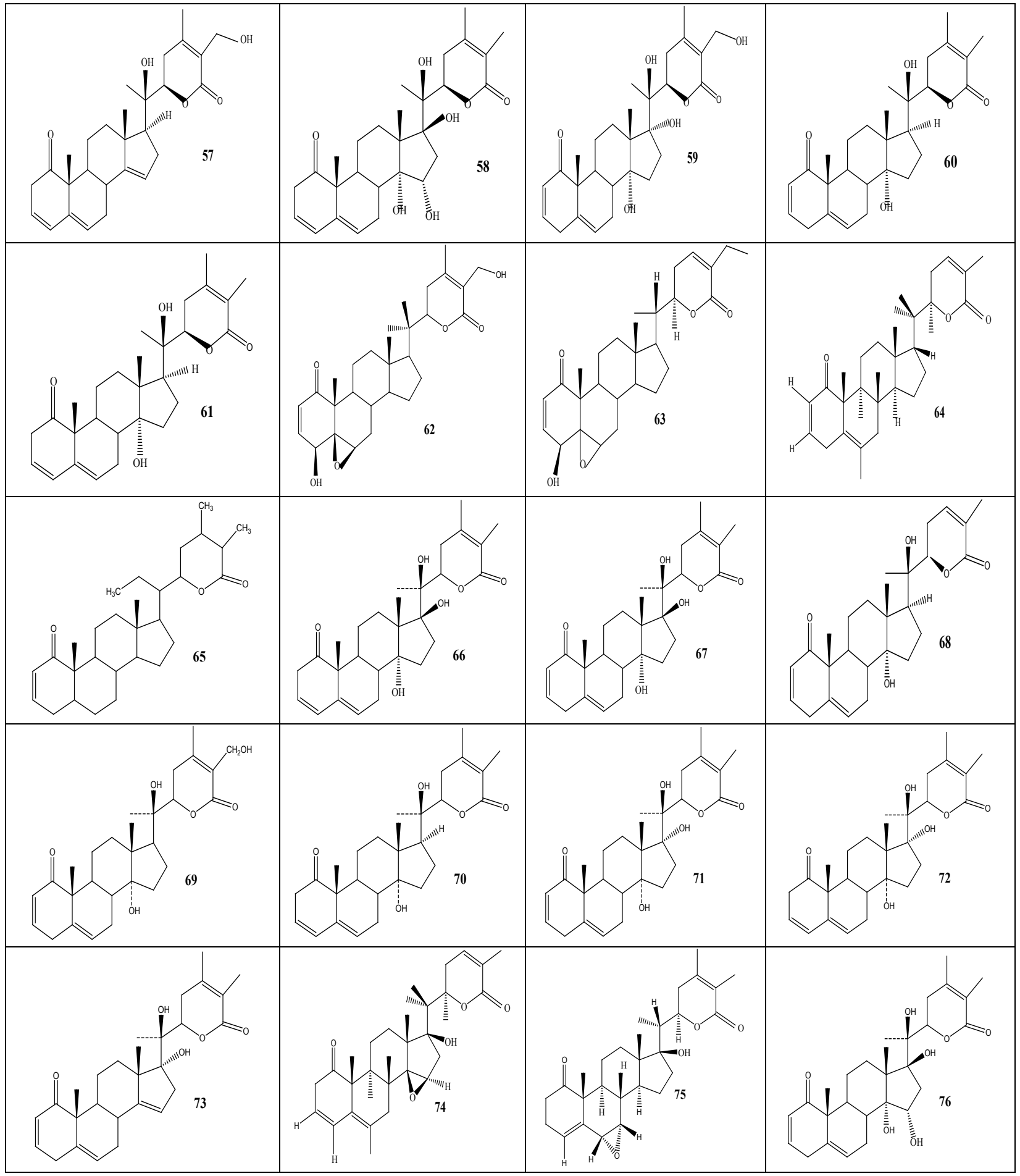

Figure 2. Structures of withanoleides for more details refer to Table 1

It showed remarkable effects in sub-acute inflammation on rats (Budhiraja et al 1984). 33-Hydroxy-2, 3- dihydrowithanolide $\mathrm{F}$ has a significant anti-inflammatory effect. It also induced hepatoxicity in adult albino rats (Budhiraja et al 1986). The hydro alcoholic extract of $W$. coagulans berry showed significant anti-inflammatory activity in carragenin induced rat paw oedema model (Rajurkar et al 2001). Lalsare and Chutervedi (2010) reported that various extracts of $W$. coagulance fruits have anti- inflammatory activities.

Inflammation is a complex process occurring through a variety of mechanisms, leading to changes of local blood flow and the release of several mediators. Arachidonic acid serves as a substrate for cyclooxygenase which catalyzes the production of prostaglandins, thromboxane and prostacyclin. Cyclooxygenase-1 (COX-1) and Cyclooxygenase-2 (COX-2) enzymes are responsible for the conversion of arachidonic acid. Prostaglandins in turn, cause inflammatory responses in the body. Selective inhibition of COX-2 enzyme by the compounds has a major advantage over nonselective nonsteroidal anti-inflammatory drugs (NSAIDs) (Jayaprakasam 
and Nair 2003). COX-2 selective inhibitors such as celecoxib, rofecoxib and valdecoxib are currently used to reduce inflammatory responses. COX-2 is expressed after an inflammatory stimulus and releases metabolites that are used to induce pain and inflammation. It is important to note that overexpression of COX-2 enzyme was observed not only in inflamed cells but also by various types of tumor cells. Hence COX-2 inhibitors with little or no COX-1 activity are of great interest for the chemoprevention of cancer (Jayaprakasam and Nair 2003). NSAIDs and COX-2 inhibitors bind to COX-2 and create a relief of the pain of inflammation. During normal physiology, COX-2 levels are undetectable, whereas the level of COX-2 is significantly higher during periods of acute and chronic inflammation (Santhi et al 2009). The anti-inflammatory activity of withanolides was assessed in vitro using leukotriene formation, COX-1 and COX-2 inhibitory assays (Wube et al 2008).

Withanolides are known as plant hormones, which can be used instead of physiological human hormones. Withanolides are amphiphilic compounds which are able to regulate activities and the physiological body hormones processes. According to a theory, when these plant hormones enter the human body, they occupy the active receptor of the cell wall, and don't allow the animal hormones to get binding to this site and express their true activities. COX-2 enzyme receptors are interested in being occupied by plant steroid hormones (Alternative Medicine Review, Monograph, 2004). Molecular docking of cyclooxygenase with a set of ligands revealed that as compared to NSAIDs, withanolides were better inhibitors of COX-2. Withanoside glycans and withanolides showed selective interaction with COX-2 better than COX-1. Therefore withanoside glycans and withanolides could be the next substitutes of NSAIDs (Nithya et al 2010).

\subsection{Anti Cancer}

Withacoagulin $\mathrm{A}$, withacoagulin $\mathrm{C}$, withacoagulin $\mathrm{D}$, withacoagulin $\mathrm{E}$, withanolide $\mathrm{L}$, , withanolide $\mathrm{J}, \Delta^{3}$ iso withanolide $F$, withanolide $F$, withacoagulin and $(22 R)$ $14 \alpha 15 \alpha 17 \beta-20 \beta$, tetrahydroxy-10xowitha $2,5,24$ trien, 26,22-olide compounds had relatively good activities (IC50<20 mm) on the inhibition of both Con A-induced T cell and LPS-induced B-cell proliferation that, among these compounds, withanolide $\mathrm{F}$ had the strongest activity $\left(\mathrm{IC} 50^{1 / 41.66 \mathrm{~mm})}\right.$ and the best SI value (25.5). Also withacoagulin $\mathrm{C}$ exhibited a satisfactory SI value. Withanolides induces apoptosis in HL-60 leukemia cells via mitochondria then the cytochrome $\mathrm{C}$ is released and caspase activation (Senthil et al 2007). 3F-hydroxy-2, 3dihydrowithanolide $\mathrm{F}$ was reported to possess anti-tumor activity (Budhiraja et al 1987). John et al (1998) reported that the extract of $W$. coagulans has the potential to inhibit thymidine incorporation and antiproliferative activity. The aqueous extract of $W$. coagulans was studied for its anti-cytotoxic effect. The extract showed remarkable DMSO (Dimethyl sulfoxide) inhibitory activity which was induced to produce cytotoxicity and decreased the TNF-G production in chicken
Lymphocyte (Chattopadhyay et al 2007). Withanolide A is well-known for its neuronal regenerating effect; it would be also dangerous to simply imply that this compound could be an excellent anti-dementia drug. It would be first necessary to investigate the side effects of the bioactive compounds and their possible interactions, to develop more clinical experiments (Mirjalili et al 2009).

It is well established that the various compounds of Withania species, such as withaferin A from the leaves, are known to posses anti-cancer properties (Jayaprakasam et al 2003). They have been reported to inhibit the cell growth of various human cancer cell lines, including lung cancer (NCI-H460). Withaferin A showed antiproliferative activity against head and neck squamous carcinoma, by reduced cell viability in cell lines in vitro (Subramanian et al 1969). This mechanism of action is a part of the result of $\mathrm{G} 2 / \mathrm{M}$ cell cycle arrest and induction of apoptosis in HNSCC cells. Withaferin A inhibited the activation of Akt and reduced total Akt levels. Additional studies will be required to evaluate the potential of withaferin A activity application, for future anticancer drug development in head and neck squamous carcinoma (Samadi et al 2010).

Phytochemical studies on withaferin A has shown cytotoxity in vitro, against $\mathrm{KB}$ cell cultures derived of intramuscular carcinoma (Fluka et al 1987). The studies also showed growth inhibitory and radio sensitizing effects in vivo on mouse Ehrlich ascites carcinoma (a transplantable, poorly differentiated malignant tumor as a spontaneous breast carcinoma in a mouse) (Devi et al 1995). Withaferin A showed significant anticancer activity in animals cell cultures by decreasing the expression of the nuclear factor-kappa $\beta$ and suppressing the intercellular tumor necrosis factor, therefore has the potential of apoptotic signaling in cancerous cell lines (Ichikawa et al 2006). Withaferin A showed inhibition growth and cytotoxic activity against human lung cancer cell lines (NCI-H460) (Choudhary et al 2010).

The mechanism by which withanolides demonstrates antiproliferative, antimetastatic, antiangiogenic, anti-invasive, and proapoptotic activities was associated with the suppression of NF-jB and NF-jB-regulated gene products (Ichikawa et al 2006). The precise role of these substances in tumor promotion is not clear, but a correlation of elevated prostaglandins in carcinogenesis has been established (Lupulescu 1978) and certain nonsteroidal anti-inflammatory agents (e.g. indomethacin and piroxicam) demonstrate chemopreventive activity assessed by Reddy et al (1992) (Atta-ur-Rahman 1998-e). It has evaluated that the plant extracts have potential to inhibit cyclooxygenase (Verma et al 1980, Jang and Pezzuto 1997). One of the most promising agents which have been identified as an inhibitor of cyclooxygenase is resveratrol. In addition to the blocking of the cyclooxygenase activity of the enzyme, the hydroperoxidase activity is inhibited. A related effect is the inhibition of COX-2 (this enzyme induced during the process of tumor promotion). So research for specific inhibitors of COX-2, versus COX-1 and a more favorable profile of activity would be anticipated 
(Jang et al 1997). The mechanism of action of COX-1 in treatment of rheumatism might be attributed to the inhibition of T- and B-cell functions (Huang et al 2009).

\subsection{Alzheimer's disease}

Pathologically, Alzheimer's disease is characterized by extracellular deposits of amyloid beta $(A \beta)$ protein and intracellular accumulation of neurofibrillary tangles (NFTs) that are composed of hyperphosphorylated tau $(\tau)$ protein (Mattson 2004; Selkoe 2001). Familial Alzheimer's has been proven to be associated with mutations in A $\beta P P$ genes (Chartier-Harlin et al 1991; Sherrington et al 1995; LevyLahad et al 1995).

Withanolide A has been studied for its potential activities against multiple associated targets with $\mathrm{A} \beta$ pathways (BACE1, ADAM10, IDE, and NEP). BACE1 (beta-site APP cleaving enzyme 1) is a rate-limiting enzyme in the production of $A \beta$ from amyloid- precursor protein (A $\beta P P)$, while ADAM10 (Disintegrin and metalloproteinase domain- containing protein 10) is involved in non- amyloidogenic processing of A $\beta P P$. IDE and NEP are two of the prominent involved enzymes in effective degrading $A \beta$. It was found out that withanolide A significantly down- regulates BACE1 and also up-regulates ADAM10 in primary rat cortical neurons. These compounds may be proven to be valuable in developing novel, effective therapeutics for the prevention and treatment of associated Alzheimer's disease with amyloid pathology (Patil et al 2010). W. coagulans has been studied for possible spasmolytic and calcium channel blocking effects. Potassium chloride $(\mathrm{KCl})$ induced contractions also the $W$. coagulans crude extract possesses calcium channel blocking activity (Ali et al 2009). Spasmolytic and $\mathrm{Ca}^{2+}$ antagonistic potentials in isolated rabbit, 5, $20 \alpha$ (R)-dihydroxy-6 $\alpha, 7 \alpha$-epoxy-1-oxo-( $5 \alpha$ )-witha-2, 24- dienolide is active on spontaneous and $\mathrm{K}^{+}$induced contractions. The cholinesterase inhibitory potential along with calcium antagonistic ability and safe profile in human neutrophil viability could make this withanolide possibly a candidate for further study to treat Alzheimer's disease and its associated problems (Choudhary et al 2005).

\subsection{Antihyperglycaemic}

The drug $W$. coagulans exhibited hypoglycaemic activity which is an effective and safe alternative treatment for diabetes (Gurson and Saner 1971; Budhiraja et al 1977; Hemalatha et al 2004). Isolated alkaloids and steroids from plant sources are responsible for hypoglycemic activity of those sources (Adebajo et al 2006). Significant improvements in symptoms and signs were observed and euglycemia was attained (diabetes mellitus type 2) by Lopez-Ridaura et al (2004) and Jaiswal et al (2009).

Also the extracted coagulin L from $W$. coagulans fruits has antihyperglycemic activity in rats (Maurya et al 2008). Lalsare and Chutervedi (2010) reported that various extracts of $W$. coagulance fruits to have anthihyperlipidemic activity. The aqueous and chloroform extracts of the fruits decreased the blood glucose $(55 \%)$, also the fruits aqueous extract decrease blood glucose by (52\%), (Hoda et al 2010). Extracted coagulin L from fruits of $W$. coagulans was determined about $25 \mathrm{mg} / \mathrm{kg}$ in streptozotocin-induced diabetic rats, which is comparable to the standard antidiabetic drug metformin (Maurya et al 2008).

The main minerals play a contributory role in enhancing hypoglycemic activity (Kar and Choudhary 1994; Kar et al 1999). Decreasing of blood glucose level and the improving of glucose tolerance test significantly showed that the higher content of $\mathrm{Mg}$ and $\mathrm{Ca}$ in $W$. coagulans is responsible for their significant role in diabetes management (Kumar et al 2009; Rai et al 2007; Giugliano et al 2000). It has been already reported that higher concentrations of $\mathrm{Mg}$ and lower concentrations of $\mathrm{K}$ play a vital roles in diabetes management (Lopez-Ridaura et al 2004, Fox et al 2001). Hence the significant antidiabetic potential of $W$. coagulans could be due to the high concentration of $\mathrm{Mg}$ along with $\mathrm{Ca}$. The $\mathrm{Ca}^{2+}$ ion activates insulin gene expression via CREB (Calcium Responsive Element Binding Protein) and is responsible for exocytose of stored insulin (Veiga et al 2006).

\section{5. Hypercholesterolemic}

The aqueous extract of $W$. coagulans fruits in high fat diet induced hyperlipidemic rats, significantly reduced elevated serum cholesterol, triglycerides, lipoprotein and the LPO levels. This drug also showed hypolipidemic activity in induced triton hypercholesterolemia. The hypolipidemic effect of $W$. coagulans fruits were found to be comparable with ayurvedic product containing Commiphora mukkul (Hemalatha et al 2006). The extracted coagulin L from fruits of W. coagulans has antidyslipidemic effect on mice (Maurya et al 2008). Hoda et al (2010) showed the aqueous and chloroform extracts of the fruits decreased triglyceride, total cholesterol, LDL and VLDL increased the HDL levels.

\subsection{Antifungal and Antibacterial Effects}

The volatile oil from the fruits of $W$. coagulans showed antibacterial activity against Staphylococcus aureus and Vibrio cholerae (Choudhary et al 1995, Khan et al 1993). Also antibacterial properties have been demonstrated for isolated withanolides from ethanolic extract of the leaves (Gaind and Budhiraja 1967). Two withanolides (14,15 $\beta$ -epoxywithanolide I [(20S,22R) 17 $\beta, 20 \beta$-dihydroxy $-14 \beta$, $15 \beta$-epoxy-1-oxo-witha-3,5,24-trienolide] and 17ß- hydroxywithanolide K (20S,22R) 14 $\alpha, 17 \beta, 20 \beta$-trihydroxy1-oxo-witha-2,5,24-trien-olide]) have been isolated from the whole plant of $W$. coagulans. The second compound was found to be active against a number of potentially pathogenic fungi (Choudhary et al 1995). The antifungal activity of the crude extract, $17 \beta$-hydroxy withanoloied $\mathrm{k}$ and withanolide $\mathrm{F}$ were tested against nine highly pathogenic isolated fungi i.e. Nigrospora oryzae, Aspergillus niger, Curvularia lanata, Pleuretus ostreatus, Stachybotrys atra, Allescheria boydii, Drechslera rostrata, Microsporum canis, and Epidermophyton floccosum. These compounds also showed activity 
against gram positive ( $S$. aureus) (Atta-ur-Rahman and Choudhary 1998). The essential oil was active against $M i$ crococcus pyogenes var. aureus and Vibro cholerae (Khare 2007). Withanolide D has antifungal cytotoxic activity on thirteen fungi which is responsible for human infectious (five dermatophytes, one nondermatophyte mold, six yeasts, and Pneumocystis carinii) (Roumy et al 2010). Lalsare et al (2010) showed antioxidant and antimicrobial activities of various extracts of $W$.coagulance fruits.

\subsection{Cardiovascular Effects}

The biosynthetic pathway lead from phytosterol precursors to the cardiac glycosides (important compounds in the treatment of cardiac insufficiency in humans) basically deduced from studies using radiolabelled precursors (Kreis and Muller-Uri 2010). An isolated new withanolide with a special chemical structure that was similar to the aglycones of the cardiac glycosides was examined for its cardiovascular effects of $W$. coagulans fruits. The withanolide caused a moderate drop of blood pressure in dogs $(34+/-2.1, \mathrm{~mm} \mathrm{Hg})$ which was blocked by atropine and not by mepyramine or propranolol. In rabbits Langendorff preparation and ECG studies, produced myocardial depressant effects but in perfused frogs hearts it caused mild positive inotropic and chronotropic effects (Budhiraja et al 1983). Extracted coagulin L from $W$. coagulans fruits also showed significant drop of a fasting blood glucose profile and improved the glucose tolerance of $\mathrm{db} / \mathrm{db}$ mice (Maurya et al 2008).

\subsection{Immunosuppressive Effects}

Withaferin $\mathrm{A}$ and withanolide $\mathrm{E}$ were reported to have specific immunosuppressive effects on human $\mathrm{B}$ and $\mathrm{T}$ lymphocytes as well as on mice thymocytes (Shohat et al 1978). The cell-mediated response is generated by various subpopulations of T-lymphocytes. These cells serve to activate various $\mathrm{T}$ effector cells that generate cell-mediated responses. The cytokines secreted by activated Th cells also regulate the proliferation and differentiation of a number of effector cells that play various roles in cell-mediated immune responses. After stimulating with PHA, T-cell progression and proliferation is depended on the cytokine production. It is obvious that the interaction between T-cells and antigens or mitogen initiates a cascade of genes expression process for proteins such as IL-2 and IFN- $\gamma$ that induces the resting $\mathrm{T}$-cells to enter the cell cycle (G0-1 transition) and contributes in the expression of the high affinity receptors for IL-2 and secretion of IL-2 (Tsai et al 2001). Inhibition of T-cell activation provides a powerful approach for immunosuppressive treatment (Mukaida et al 1994).

A known withanolide, coagulin- $\mathrm{H}$, was evaluated for its effect on various cellular functions related to immune responses including lymphocyte proliferation, interleukin-2 (IL-2) cytokine expression. These results were compared with prednisolone. Coagulin-H was found to have a powerful inhibitory effect on lymphocyte proliferation and the Th-1 cytokine production. The inhibition of the phytohaemagglutinin (PHA) activated $\mathrm{T}$-cell proliferation by coagulin- $\mathrm{H}$ (Mesaik et al 2006).

\section{Another Activity}

i. Furthermore, $W$. coagulans has wound healing activities in streptozotocin-induced diabetic rats. The hydroalcoholic fraction of $W$. coagulans in oral form is found to be more effective than the aerial part of Aloe barbadensis Miller which is used as a local demulcent in wounded diabetic rats. Prasad et al (2010) showed that withaferin-A is responsible for increasing the collagen significant levels, protein, DNA, SOD, CAT and hexosamine decreasing.

ii. As Siddiqui et al (1963) studies showed the extract of Withania coagulans is muscular relaxing in experimental animals and is also a hypotensive, respiratory stimulant.

iii. The protective effect of obtained 3F-hydroxy-2, 3 dihydro-withanolide $\mathrm{F}$ from $W$. coagulans fruits was studied against the hepatotoxicity, induced by $\mathrm{CCl}_{4}$. Budhiraja et al (1984) showed that the protective effect of withanolide F was more active than hydrocortisone.

iv. The aqueous extract exhibited free radical scavenging activity in an in vitro system using DPPH (Budhiraja et al 1986). Fruits extracts of $W$. coagulans have antioxidant potential against several diseases such as ageing, artherosclerosis etc. which caused due to ROS. (Mathur et al. 2011)

v. Based on Karami et al (2006) the root extract of $W$. coagulans had significant effects on the withdrawal syndrome in mice. It also showed significant suppression of morphine withdrawal jump, induced by naloxone, and decreased the development of morphine dependence.

vi. Using the aqueous extract of $W$. coagulans fruits in experimental rats have a diuretic potential. Withanolides from $W$. coagulans are more polar in nature compared to the other Withania species. The diuretic effects may be associated with the presence of the active principles of polar nature where withanolides are the main chemical protagonist of this activity. Dabheliya et al (2010) investigation's supports using $W$. coagulans as the diuretic agent in traditional folklore medicine.

vii. A steam volatile oil of the petroleum ether extract of $W$. coagulans has been found to possess lethal effect on earthworms (Gaind and Budhiraja 1967). The aerial parts of $W$. coagulans have anthelmintics in ruminants (Jabbar et al 2006). Also Khare reported an anthelmintic activity for $W$. coagulans (Khare et al 2007).

\section{Conclusions}

The fruit, leaves and root of Withania coagulans have been used as a treatment in many disorders. It's found to be rich source of esterases, free amino acids, fatty oils, essential oils and withanolides. Withanolides are steroidal lactones and several of them possess significant pharmacological 
activities. Hence, further structure-activity relationship investigations and possible optimization of their non-toxic and diffusion properties would be interesting. In addition, future studies should lead to synthesis of these complex and fascinating chemical structures and their generics via modification/addition of different functional groups. It is also important to reveal the bio-efficacy of isolated compounds in combination with other herbs or drugs. Moreover, it is also necessary to study the effects and mechanisms of the isolated molecules in vivo using suitable higher animals to ensure its potentiality and safety. The present review comprehensively enlists the isolated compounds. It also describes the remedial qualities and the molecular mechanism of action.

\section{ACKNOWLEDGEMENTS}

The authors are very grateful to dr J. walisade who recommended this plant for research and to dr H.R. shaterian, dr N. kazemipour and dr M. Kaykhaii in recognition of their favourable help in the early stages of the research of this article.

\section{REFERENCES}

[1] Adebajo A, Ayoola O, Iwadewa E, Akindahunsi A, Omisore N, Adewunmi C, Adenowo T (2006) Antitrichomonal, biochemical and toxicological activities of methanolic extract and some carbajole alkaloids isolated from the leaves of Murraya koenigii growing in Nigeria. Phytomedicine 13(4): 246-54

[2] Ali N, Ahmad B, Bashir S, Shah J, Azam S, Ahmad M (2009) Calcium channel blocking activities of Withania coagulans. AJPP 3(9): 439-442

[3] Alternative Medicine Review, (2004) Monograph 9 (2): 211-214

[4] Anonymous (1996) The wealth of India, Publication and information directorate. Council of Scientific and Industrial Research, New Dehli: 947-949

[5] Atal CK, Sethi PDA (1963) Preliminary chemical examination of Withania coagulans. Indian J. Pharm 25: 163-164

[6] Atta-ur-Rahman, Abbas S, Dur-E-Shahwar, Jamal SA, Choudhary MI (1993) New withanolides from Withania sp. J Nat Prod 56 (7): 1000-1006

[7] Atta-ur-Rahman and Choudhary MI (1998) New natural products from medicinal plants of Pakistan. PURE APPL CHEM 70 (2): 385-389

[8] Atta-ur-Rahman, Choudhary MI, Qureshi S, Gul W, Yusaf M, (1998a) Two new ergostane- type steroidal lactones from Withania coagulans. J NAT PROD 61(6): 812- 814

[9] Atta-ur-Rahman, Choudhary MI, Yousaf M, Gul W, Qureshi S (1998b) New withanolides from Withania coagulans. Chem. Pharm. Bull 46(12): 1853-1856

[10] Atta-ur-Rahman, Dur-e-Shahwar, Naz A, Choudhary MI,
(2003) Withanolides from Withania coagulans. Phytochemistry $63: 387-390$

[11] Atta-ur-Rahman, Shabbir M, Dur-e-Shahwar, Choudhary MI, Voelter W, Hohnholz D (1998c) New steroidal lactones from Withania coagulans. Heterocycles 47 (2):1005-1012

[12] Atta-ur-Rahman, Shabbir M, Yousaf M, Qureshi S, Dur-e-Shahwar, Naz A, Choudhary MI (1999) Three withanolides from Withania coagulans. Phytochemistry 52 (7): $1361-1364$

[13] Atta-ur-Rahman, Yousaf M, Gul W, Qureshi S, Choudhary MI, Voelter W, Hoff A, Jens F, Naz A (1998d) Five new withanolides from Withania coagulans. Heterocycles 48: $1801-1811$

[14] Atta-ur-Rahman (1998 e) Studies in Natural Products Chemistry: Structure and Chemistry (Part F), Vol 20. Elsevier Science, Amsterdam

[15] Beers SA, Iamakura Y, Dai HJ, Li DH, Cheng YC, Lee KH (1988) Antitumor agents, 99. Synthetic ring C aromatized podophyllotoxin analogues as potential inhibitors of human DNA topoisomerase II. J NAT PROD 51: 901

[16] Budhiraja RD, Sudhir S, Garga KN (1977) Pharmacological investigations on fruits of Withania coagulans Dunal. Planta Medica 32: 154-57

[17] Budhiraja RD, Sudhir S, Garg KN, Arora B (1986) Protective effect of 3 beta-hydroxy-2, 3 dihydro withanolide $F$ against CCl4 induced hepatotoxicity. Planta Medica 1: 28-29

[18] Budhiraja RD, Sudhir S, Garg KN, Arora BC (1984) Antiinflammatory activity of $3 \beta$-Hydroxy-2, 3-dihydro-withanolide F. Planta Medica 50 (2): 134-136

[19] Budhiraja RD, Sudhir S, Garg KN, Arora BC (1987) Review of biologicl ativity of Withanolides. J SCI IND RES 46 (11): 488-491

[20] Budhiraja RD, Sudhir S, Garg KN (1983) Cardiovascular effects of a withanolide from Withania coagulans Dunal. fruits. Indian J Physiol Pharmacol 27 (2):129-134

[21] Chartier-Harlin MC, Crawford F, Houlden H, Warren A, Hughes D, Fidani L, Goate A, Rossor M, Roques P, Hardy J, Mullan M, (1991) Early-onset Alzheimer's disease caused by mutations at codon 717 of the beta-amyloid precursor protein gene. Nature 353: 844-846

[22] Chattopadhyay P, Mahaur K, Saha SK, Singh L, Shukla G, Wahi AK (2007) Effect of aqueous extract of fruits of Withania coagulans on cytotoxicity and tumor necrosis factorproduction in chicken lymphocytes. Indian J Nat Prod 23(3): $8-12$

[23] Choudhary MI, Nawaz SA, Haq Zu, Arif Lodhi M, Ghayur MN, Jalil S, Riaz N, Yousuf S, Malik A, Gilani AH, Atta-ur-Rahman (2005) Withanolides, a new class of natural cholinesterase inhibitors with calcium antagonistic properties. BIOCHEM BIOPH RES CO 334(1): 276-287

[24] Choudhary MI, Dur-E-Shahwar, Zeba P, Jabbar A, Ali I, Atta-ur- Rahman (1995) Antifungal steriodal lactones from W. coagulans. Phytochemistry 40:1243-1246

[25] Choudhary MI, Hussain S, Yousuf S, Mudassar AD, Atta-urRahman (2010) Chlorinated and diepoxy withanolides from Withania somnifera and their cytotoxic effects against human 
lung cancer cell line. Phytochemistry 71: 2205-2209

[26] Dabheliya J, Khan SA, Joshipura M, Vasoya M, Patel S, Vijaya S (2010) Duretic potential of Aueous extract of fruits of W. coagulans Dunal in experimental rats. IJPPS 2: 4

[27] Devi PU, Sharada AC, Solomon FE (1995) In vivo growth inhibitory and radiosensitizing effects of withaferin A on mouse Ehrlich ascites carcinoma. CANCER LETT 95(1-2): 189-193

[28] Dur- E- Shahwar (1999) Isolation and structural studies on the withanolidal constituents of Withania coagulans, $\mathrm{PhD}$ thesis, International center for chemichal sciences H.E.J. Research Institute of Chemistry, University of Karachi, Karachi

[29] Dymock W, Warden CJH, Hooper D (1893) Pharmacographia Indica. In: Kegan Paul (ed) Index and appendix to the Pharmacographia Indica. Trench \& Trubner Co, London

[30] Eich E, (2008) Solanaceae.and Convolvulaceae. Secondary Metabolites. Springer-Verlag, Berlin Heidelberg

[31] Fluka J, Proksa B, Williamson J, Rosazza FJP (1987) Microbiol. 32: 112

[32] Fox C, Ramsoomair D, Carte C (2001) Magnesium, its proven and potential clinical significance. SOUTHERN MED J 94 (12): 1195-1201

[33] Gaind KN, Budhiraja RD (1967) Antibacterial and anthelmintic activity of Withania coagulans Dunal. Indian J. Pharm 29:185-186.

[34] Giugliano M, Bove M, Grattaro M (2000) Insulin release at the molecular level, metabolic electro physiological modeling of pancreatic â-cells. IEEE Trans. Biomed. Eng. 47: 611-23

[35] Glotter E (1991)Withanolides and related ergostane-type steroids. NAT PROD REP 8: 415-40

[36] Gurson CT, Saner G (1971) Effect of chromium on glucose utilization in marasmic protein calorie mal nutrition. AM J CLIN NUTR 24: 1313-1319

[37] Hemalatha S, Wahi AK, Singh PN, Chansuria JP (2004) Hypoglycemic activity of Withania coagulans Dunal. in streptozotocin induced diabetic rats. J ETHNOPHARMACOL. 93: 261

[38] Hemalatha S, Wahi AK, Singh PN, Chansuria JP (2006) Hypolipidemic Activity of Aqueous Extract of Withania coagulans Dunal in Albino Rats. PHYTOTHER RES. 20:614

[39] Hemalatha S, Kumar R, Kumar M (2008) Withania coagulans Dunal: A Review, Phcog. Rev 2(4): 351-358

[40] Hoda Q, Ahmad S, Akhtar M, Najmi AK, Pillai K, Ahmad SJ (2010) Antihyperglycaemic and antihyperlipidaemic effect of poly-constituents, in aqueous and chloroform extracts, of Withania coagulans Dunal. in experimental type 2 diabetes mellitus in rats. Hum Exp Toxicol 29 (8): 653-658

[41] Huang CF, Ma L, Sun LJ, Ali M, Arfan M, Liu JW, Hu LH (2009) Immunosuppressive Withanolides from Withania coagulans. CHEM BIODIVERS 6: 1415-1426

[42] Huang Y, Liu JK, Mühlbauer A, Henkel T (2002) three novel taccalonolides from the tropical plant Tacca subflaellata. HELV MED ACTA 85: 2553-2558

[43] Ichikawa H, Takada Y, Shishodia S, Jayaprakasam B, Nair
MG, Agarwal BB (2006) Withanolides potentiate apoptosis, inhibit invasion, and abolish osteoclastogenesis through suppression of nuclear factor-kappaB (NF-kappaB) activation and NF-kappaB-regulated gene expression. MOL CANCER THER 6: 1434-1445

[44] Jabbar A, Raza MA, Iqbal Z, Khan MN (2006) Ethnopharmacological communication an inventory of the ethnobotanicals used as anthelmintics in the southern Punjab (Pakistan). J ETHNOPHARMACOL 108:152-154

[45] Jahan E, Perveen S, Fatima I, Malik A (2010). Coagulansins $\mathrm{A}$ and B, New Withanolides from Withania coagulans Dunal. HELV CHIM ACTA 93:530-535

[46] Jaiswal D, Rai PK, Watal G (2009) Antidiabetic effect of Withania coagulans in experimental rats. Indian J Clin Biochem 24 (1): 88-93

[47] Jang M, Cai L, Udeani GO, Slowing K, Thomas CF, Beecher CWW, Fong HHS, Farnsworth NR, Kinghorn AD, Mehta RG, Moon RC, Pezzuto JM (1997) Cancer chemopreventive activity of resveratrol, a natural product derived from grapes. Science 275:218-220

[48] Jang MS, Pezzuto JM (1997) Assessment of cyclooxygenase inhibitors using in vitro assay systems. Meth. Cell Sci 19:25-31

[49] Jayaprakasam B, Nair MG (2003) Cyclooxygenase-2 enzyme inhibitory withanolides from Withania somnifera leaves. Tetrahedron 59:841-849.

[50] Jayaprakasam B, Zhang Y, Seeram NP, Nair M G (2003) Growth inhibition of human tumor cell lines by withanolides from Withania somnifera leaves. LIFE SCI 74:125-132

[51] Kar A, Choudhary B K (1994) Important mineral content of a few ayurvedic herbs with a discussion on medicinal aspects. Indian Drugs 31(3):127-130

[52] Kar A, Choudhary BK, Bandyopadhyay NG (1999) Preliminary studies on the inorganic constituents of some indigenous hypoglycemic herbs on oral glucose tolerance test. J ETHNOPHARMACOL 64(2):179-184

[53] Karami M, Gohari AR, Ebrahimzadeh MA (2006) Effect of Withania coagulans root extraction the withdrawal syndrome in mice. Pharmacologyonline 3:166-171

[54] Khan MTJ, Ashraf M, Tehniyat S, Bukhtair MK, Ashraf S, Ahmed W (1993) Anti bacterial activity of W.coagulans. Fitoterapia $64: 367$

[55] Khan PM, Malik A, Ahmad S, Nawaz HR (1999) Withanolides from Ajuga parviflora. J NAT PROD 62:1290-1292

[56] Khare CP (2007) Indian Medicinal Plants. Springer-Verlag, Berlin/Heidelberg

[57] Kirthikar KR, Basu BD (1933) Indian Medical Plants. 2d ed. Bishen Singh Mahendra Pal Singh, Delhi

[58] Kreis W, Muller-Uri F (2010) Biochemistry of sterols, cardiac glycosides, brassinosteroids, phytoecdysteroids and steroidsaponins.In: Michael W (ed) Annual Plant Reviews, vol 40. Wiley-Blackwell, Singapore, pp304-363

[59] Lalsare S, Chatervedi A, Rajurakar S, Verma PK, Sharma D (2010) Antioxidant and antimicrobial activity of various ex- 
tract of fruits of Withania coagulance - Dunal. With chemical characterization. Pharmacology online. 1:902-912

[60] Lalsare S, Chutervedi A (2010) Anti-inflammatory and anthihyperlipidemic activity of various extract of fruits Withania coagulance. Pharmacologyonline 1:101-107

[61] Lavie D, Glotter E, Shvo Y (1965 a) Constituents of Withania somnifera. III. The side chain of withaferin A. J ORG CHEM 30:1774-1778

[62] Lavie D, Glotter E, Shvo Y (1965 b) Constituents of Withania somnifera. IV. The structure of withaferin A. J. Chem. Soc IV: 7517-7531

[63] Levy-Lahad E, Wasco W, Poorkaj P, Romano DM, Oshima J, Pettingell WH, Yu CE, Jondro PD, Schmidt SD, Wang K, Crowley AC, Fu Y-H., Guenette S Y, Galas D, Nemens E, Wejsman E M, Bird T D, Schellenberg G D, Tanzi R E (1995) Candidate gene for the chromosome 1 familial Alzheimer's disease locus. Science 269:973-977

[64] Lopez-Ridaura R, Willett W C, Rim E B, Liu S, Stampfer M J, Manson J E, Hu F B (2004) Magnesium intake and risk of type 2 diabetes in men and women. Diabetes Care 27(1):134-140

[65] Lupulescu A (1978) Enhancement of carcinogenesis by prostaglandins. Nature 272:634-636

[66] Mathur D, Agrawal RC and Shrivastava V (2011) Phytochemical Screening and Determination of Antioxidant Potential of Fruits Extracts of Withania coagulans, RRST-Phytochemistry 3(11): 26-29

[67] Mattson M P (2004) Pathways towards and away from Alzheimer's disease. Nature 431:631-639

[68] Maurya R, Akanksha, Jayendra, Singh A, Srivastava AK (2008) Coagulanolide, a withanolide from Withania coagulans fruits and antihyperglycemic activity. BIOORG MED CHEM LETT 18:6534-6537

[69] Mesaik MA, Haq Zu, Muradb S, Ismail Z, Abdullah NR, Gill HK, Atta-ur-Rahman, Yousaf M, Siddiqui RA, Ahmade A, Choudhary MI (2006) Biological and molecular docking studies on coagulin-H, Human IL-2 novel natural inhibitor. MOL IMMUNOL 43:1855-1863

[70] Mirjalili MH, Moyano E, Bonfill M, Cusido R M, Palazón J (2009) Steroidal Lactones from Withania somnifera, an Ancient Plant for Novel Medicine. Molecules 14:2373-2393

[71] Nawaz HR, Malik A, Khan PM, Ahmed S (1999) Withanolides from Ajuga parviflora,. Phytochemistry 52:1357

[72] Naz A (2002) Studies on the Chemical Constituents of Withania coagulans and Boswellia dalzielli. P.H.D thesis, International center for chemical siences university of Karachi, Pakistan

[73] Naz S, Masud T, Nawaz MA (2009) Characterization of milk coagulating properties from the extract of Withania coagulans. INT J DAIRY TECHNOL 62:315-20

[74] Neogi, Partha, Kawai, Masao, Butsugan, Yasuo, Mori, Yuji, Suzuki, Makoto (1988) Withacoagin, a new withanolide from Withania coagulans roots. B CHEM SOC JPN 61(12): $4479-4481$

[75] Nithya K, Vinithra I, Kalaiselvi K (2010) Homology model- ing of cyclooxygenase and insilico analysis of interaction between cyclooxygenase and withanolides. Paper presented at the 3rd Indo Korean Joint Seminar on Medicinal Plant Research (IKMPR-2010)

[76] Nur-e-Alam M, Yousaf M, Qureshi S, Baig I, Nasim S, Atta-ur-Rahman, Choudhary MI (2003) A Novel Dimeric Podophyllotoxin-Type Lignan and a New Withanolide from Withania coagulans. HELV CHIM ACTA 86(3):607-614

[77] Patil SP, Maki S, Khedkar SA, Rigby AC, Chan C (2010) Withanolide A and Asiatic Acid Modulate Multiple Targets Associated with Amyloid-_Precursor Protein Processing and Amyloid-Protein Clearance. J NAT PROD 73:1196-1202

[78] Pezzuto JM, Angerhofer CK, Mehdi H (1998) In Vitro Models of Human Disease States. In: Atta-ur-Rahman (ed) Studies in Natural Products Chemistry: Structure and Chemistry (Part F), Vol 20. Elsevier Science, Amsterdam, vol 20, pp507-560

[79] Prasad SK, Kumar R, Patel DK, Hemalatha S (2010) Wound healing activity of Withania coagulans in streptozotocin-induced diabetic rats. Pharm Biol 48 (12):1397-1404.

[80] Rai PK, Rai NK, Rai AK, Watal G (2007) Role of LIBS in elemental analysis of Psidium guajava responsible for glycemic potential. INSTRUM SCI TECHNOL 35(5):507-22

[81] Rajurkar SM, Thakre PN, Waddukar S G (2001) Phytochemical \& pharmacological screening of Withania coagulans berries as anti inflammation. Paper presented at the 53rd Indian pharmaceutical congress, New Delhi, CP 38, 215

[82] Roumy V, Biabiany M, Hennebelle T, Aliouat ElM, Pottier M, Joseph H, Joha S, Quesnel B, Alkhatib R, Sahpaz S, Bailleul F (2010) Antifungal and Cytotoxic Activity of Withanolides from Acnistus arborescens. J NAT PROD 73:1313-1317

[83] Samadi AK, Tong X, Mukerji R, Zhang H, Timmermann BN, Cohen M S (2010). Withaferin A, a cytotoxic steroid from vassobia brewiflora, Induces apoptosis in human head and neck squamous cell cssarcinoma. J NAT PROD 73:14761481

[84] Santhi N, Rajeshwari M, Senthil K, Parvatham R, (2009) Identification of potential anti-inflammatory bioactive compounds from Withania somnifera (L.) Dunal. Molecular docking studies using glide

[85] Selkoe DJ (2001) Alzheimer's disease: genes, proteins, and therapy. Physiol Rev 81: 741-766

[86] Senthil V, Ramadevi S, Venkatakrishnan V, Giridharan P, Lakshmi BS, Vishwakarma RA, Balakrishnan A (2007) Withanolide induces apoptosis in HL-60 leukemia cells via mitochondria mediated cytochrome c release and caspase activation. CHEM-BIOL INTERACT 167:19-30

[87] Sherrington R, Rogaev EI, Liang Y, Rogaeva EA, Levesque G, Ikeda M, Chi H, Lin C, Li G, Holman K, Tsuda T, Mar L, Foncin J F, Bruni A C, Montesi M P, Sorbi S, Rainero I, Pinessi L, Nee L, Chumakov I, Pollen D, Brookes A, Sanseau P, Polinsky R J, Wasco W, Da Silva H A R, Haines J L, Pericak-Vance M A, Tanzi R E, Roses A D, Fraser P E, Rommens J M, St George-Hyslop P H (1995) Cloning of a gene bearing missense mutations in early-onset familial Alzheimer's disease. Nature 375:754-760.

[88] Shohat B, Kirson I, Lavie D (1978) Immunosuppressive activity of two plant steroidal lactones withaferin A and withanolide E. Biomedicine 28:18-24 
[89] Siddiqui HH, Israili AH, Qadry SMJS (1963) Studies on Withania coagulans Dunal. (PART I), Planta Medica. 2:145

[90] Sinha SC, Kundu S, Maurya R, Ray AB, Oshima Y, Bagchi A, Hikino H (1989) Tetrahedron. 45:2165-2176

[91] Subramanian SS, Sethi PD (1969) Withaferin-A from the roots of Withania coagulans. CURR SCI INDIA 38 (11): 267-268

[92] Subramanian SS, Sethi PD, Glotter E, Kirson I, Lavie D

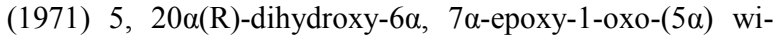
tha-2, 24-dienolide, a new steroidal lactone from withania coagulans. Phytochemistry. 10:685

[93] Tsai T, Hseih C, Lin Y, Tsai W, Kuo Y-C (2001) Enhancement of cell proliferation and cytokines production in human peripheral blood mononuclear cells by extracts from blood enriching Dang-Qui decoction. J Chinese Medicine 12:191-202

[94] Veiga S, Leonelli E, Beelke M, Gareia-Segura V M, Melcangi
R C (2006) Neuroactive steroids prevent peripheral myelin alterations induced by diabetes. NEUROSCI LETT 402(12):150-53

[95] Velde VV, Lavie D (1981). New withanolieodes of biogenetic interest from Withania Somnifera. Phytochemistry 20:1359

[96] Velde VV, Lavie D, Budhiraja RD, Sudhir S, Garg K N (1983) Potential biogenetic precursors of withanolides from withania coagulans. Phytochemistry 22(10):2253-2257

[97] Verma AK, Ashendel CL, Boutwell R K (1980). A nonsteroidalanti-inflammatory agent which inhibits the activity of cyclooxygenase and the inductionof ornithine decarboxylase. CANCER RES 40:308-315

[98] Wube A A, Wenzig E M, Gibbons S, Asres K, Bauer R, Bucar F (2008) Constituents of the stem bark of Discopodium penninervium and their LTB4 and COX-1 and -2 inhibitory activities. Phytochemistry 69:982-987 